\title{
THE FUTURE OF COMPUTER CHESS
}

\author{
T.A. Marsland \\ ICCA President
}

Edmonton, Alberta, Canada

\begin{abstract}
Computer-Chess Events have a long and illustrious history, beginning with New York in August 1970, when Monty Newborn and his organizing committee put together the first computer-chess tournament. From the earliest annual events in America, which used state-of-the-art technology (acoustic couplers!) for linking terminals and remote computers, through the first World Championship in Stockholm in 1974 - when a concerted effort was made to have at least one competitor from each contributing country - to the introduction in 1980 of the first event exclusively for on-site micro-computers, an enthusiastic band of participants and organizers have worked to make things happen. Although solid chess programs, notably MacHack 6, were established prior to 1970, it was the participants to that first event who inevitably led the formation of the International Computer Chess Association, dedicated to the support and encouragement of chess programmers. Those of us who have been involved since that time get some satisfaction from being around while history is made, and have looked forward with excitement to the DEEP BLUE against Kasparov match in February.
\end{abstract}

Our regular events have grown steadily over the years. The 1995 year saw the $8^{\text {th }}$ World Championship in Hong Kong, where the strongest chess programs were brought together to provide an open competition between remote giant computers and highly-tuned opponents using local top-of-the-line microcomputers. Later that year the $13^{\text {th }}$ Microcomputer Chess Championship took place in Paderborn, Germany, where even though the remote computers were excluded - the ranks swelled from 24 competitors to 33 (the largest ever for an event of this type). With all these rapid developments and changes the future for computer-chess events seems to be very bright. The very existence of Gary "Kasparov's" upcoming match against DEEP BLUE, hosted by the ACM and run under the auspices of the ICCA, signals an additional level of recognition for computer chess. Just as the ICCA's regular championships continue to grow in importance, so does interest in events such as the AEGON Tournament, the Harvard Cup, and the INTEL Chess Challenge. Nevertheless, who will find the time and money to make all this possible?

Questions like this must be asked and addressed quite quickly, because the lead time in planning a major event increases and the financial support necessary to make Computer Chess Championships possible is increasingly significant. Many people do not know that it cost about $\$ 60,000$ to host the 1989 World Championship in Edmonton, that $\$ 80,000$ was provided to put on the 1992 Championship in Madrid or that about $\$ 90,000$ was used to put on recent event in Hong Kong. These are substantial sums, and yet they are necessary to provide travel and accommodation support for the best participants, to pay for telecommunication costs and equipment rental, to handle room charges and receptions, and to pay the Tournament Director and other organizational costs, including support for our excellent Journal, where the latest techniques, developments, and news about computer chess are published.

What then can the average ICCA member do to ensure the success of the $9^{\text {th }}$ World Computer Chess Championship, scheduled for 1998? The most important aspect of hosting an event is finding sponsorship. In addition to the cash funding we need not only use of a suitable tournament room, but also sundry items such as chess sets and clocks. But once the money is committed and the event assured, the other details always fall into place. Of course we need the help of a dedicated enthusiast, such as Hon Ki Tsang who handled the local arrangements and publicity in Hong Kong, but the ICCA guides local organizers smoothly through these various tasks. Generally the sponsor controls the choice of location, but finding a sponsor can take considerable time and energy, in my experience.

1 University of Alberta, Computing Science Department, Edmonton, Alberta, Canada T6G 2H1.

Email: tony@cs.ualberta.ca. 
Unlike FIDE, we do not operate a system of options nor do we auction events to the highest bidder. Our standard terms are as follows: we tell anyone who expresses an interest how much it will cost to host an ICCA event, and then we accept the first bid that meets our criteria. We have found this approach to work well in the past - since it overcomes the problem with options that are not taken up, where we may be left with a narrower time-frame in which to find a replacement site.

The ICCA board estimates the cost of hosting the 1998 World Computer Chess Championship at $\$ 125,000$. Since that is an open event, we will also need several international phone links to the site. We envision that, with adequate support, an associated human vs computer team match should also be possible.

Where then might the 1998 Championship be held? In truth anywhere, though some ICCA members have noted the lack of regional computer-chess events in America, when compared to the Dutch and German Championships. Since 1970, and for about twenty-five years, the premier North American event has been the ACM International Computer Chess Championship. Sanctioned by the ICCA and organized by a dedicated committee, this event has been a testing ground for many a new idea. These events have always been well organized and controversy-free, thanks to the popular director-commentator Mike Valvo. In the earlier years it was also quite lively with great audience participation stimulated by David Levy's sharp observations. But as the programs grew better, the commentator's opportunities to involve the audience became less frequent. So times change and we must be ready to incorporate new ideas and new energy from another generation of people with vision.

What form might future American events take? Although is not so clear, there is still time for ICCA members and others to not only provide input, but also to add their voice to mine in thanking the ACM for embracing so warmly our American event, and to let them know how much we, of the ICCA, appreciate their continuing support for this historic and scientific activity.

That said, perhaps these events should have more human interaction, and more high-tech multimedia pizzazz? From the 1994 INTEL Chess Express Challenge we saw clearly how FRITZ 3 could outlast even the best humans at speed chess. Shortly after that success, CHESS GENIUS undercut some top competitors in INTEL's speed-chess Grand Prix, including Kasparov himself. Perhaps the ICCA should be more involved in this type of event, broadening its mandate beyond that of providing a support group for active chess programmers? That said, these changing times require us to find more sponsors and the current organizers need concrete offers of help if the premier computer-chess event in the United States is to keep going in one guise or another. Certainly the ICCA recognizes its obligation and need to keep computer chess and its downstream industry alive and well, but we need help to cultivate and improve our contacts with potential sponsors.

While the cost of a world championship is high, the annual Microcomputer Championship (11-round Swiss, played over 8 days) is normally very much lower. Traditionally that event has been in Europe where $90 \%$ of the participants can travel by car and stay in budget hotels. Since participants can bring their own equipment, and since there are no telecommunication costs, the overheads are significantly lower. Although the ICCA has all the talent and experience it needs to run the events, a sponsor is necessary to cover the sanctioning fee and organizing expenses. To this end we are willing to negotiate a service fee with anyone who successfully raises funds for any ICCA event.

Thus with this message I urge all people who are interested in seeing the continuation of our fine tradition of Computer Chess Championships to work with the ICCA Executive to bring our activities to the attention of any, indeed all, potential sponsors. In return we will see that a first-class event takes place. Ideally computer chess adds an international component to a national meeting of almost any kind, whether cultural and historic, or something that embraces the latest computer and network technology. Such international events have attracted considerable press and TV coverage in the past. This then makes it possible for sponsors to raise their profile, both locally and around the globe. The ICCA has been proactive in this matter and we are pleased to acknowledge our role in the Association for Computing Machinery's $50^{\text {th }}$ anniversary and their Kasparov against DEEP BLUE match. Held under the auspices of the ICCA, it was our job to ensure that this event ran smoothly and according to the agreed terms. For the future, though, the ICCA needs concrete support from all quarters to sustain events in North America and worldwide. 